\title{
Orthodox etching of HVPE-grown GaN
}

\author{
J.L. Weyher ${ }^{1,2^{*}}$, S. Lazar ${ }^{3}$, L. Macht ${ }^{1}$, Z. Liliental-Weber ${ }^{4}$, R.J. Molnar ${ }^{5}$, S. Muller ${ }^{6}$, G. Nowak ${ }^{2}$, I. \\ Grzegory $^{2}$ \\ 1) Applied Materials Science, Radboud University Nijmegen, Toernooiveld 1, 6525 ED Nijmegen, The \\ Netherlands \\ 2) High Pressure Research Center, Polish Academy of Sciences, ul. Sokolowska 29/37, 01-142 Warsaw, \\ Poland \\ 3) Kavli Institute of Nanoscience, Delft University of Technology, Lorentzweg 1, 2628CJ Delft, The \\ Netherlands \\ 4) Lawrence Berkeley National Laboratory, Berkeley, CA 94720, USA \\ ${ }^{5)}$ Massachusetts Institute of Technology, Lincoln Laboratory, Lexington, MA, USA 02420-9108 \\ ${ }^{6)}$ FhG-IAF, Tullastr. 72, D-79108 Freiburg i. Br., Germany \\ ${ }^{*}$ Corresponding author: J.Weyher@science.ru.nl
}

\begin{abstract}
Orthodox etching of HVPE-grown $\mathrm{GaN}$ in molten eutectic of $\mathrm{KOH}+\mathrm{NaOH}$ (E etch) and in hot sulfuric and phosphoric acids (HH etch) is discussed in detail. Three size grades of pits are formed by the preferential $\mathrm{E}$ etching at the outcrops of threading dislocations on the Ga-polar surface of GaN. Using transmission electron microscopy (TEM) as the calibration tool it is shown that the largest pits are formed on screw, intermediate on mixed and the smallest on edge dislocations. This sequence of size does not follow the sequence of the Burgers values (and thus the magnitude of the elastic energy) of corresponding dislocations. This discrepancy is explained taking into account the effect of decoration of dislocations, the degree of which is expected to be different depending on the lattice deformation around the dislocations, i.e. on the edge component of the Burgers vector. It is argued that the large scatter of optimal etching temperatures required for revealing all three types of dislocations in HVPE-grown samples from different sources also depends upon the energetic status of dislocations. The role of kinetics for reliability of etching in both etches is discussed and the way of optimization of the etching parameters is shown.
\end{abstract}

\section{Introduction}

Defect-selective etching is one of the cheapest and time-effective methods used for revealing and analysis of dislocations in semiconductors. Every new etch requires verification of its reliability: both optimized etching conditions for revealing all defects and unequivocal interpretation of the meaning of the etch features have to be established. Different approaches were used for this purpose, e.g.: direct calibration by X-ray topography [1] (suitable for dislocation density below $10^{5} \mathrm{~cm}^{-2}$ ), comparison with cathodoluminescence (CL) [2], electron beam induced current (EBIC) [3] or another calibrated etching method [4], sequent etching [5] and calibration by TEM, as in e.g. [4-8]. Among these methods the latter is the most attractive because it offers the possibility of establishing not only the one-to-one correspondence between the etch features and the individual defects but also to establish a correlation between different features and their causative defects. As a result TEM, has been the main technique used for calibration of recently developed defect-selective etching methods for $\mathrm{GaN}$ [9-11]. Two approaches are usually employed for this purpose, namely (i) comparison of dislocation density established by TEM with the density of etch pits (etch features), e.g. [9] and (ii) examination of thin foils prepared from the etched samples using either conventional cross-section specimens $[6,10]$ or focus ion beam (FIB) [12]. For calibration of the orthodox etching method, which reveals dislocations in the form of pits, the latter approach is the most favorable because it yields a direct association of the etch feature with the underlying defect. 
TEM was most frequently used for calibration of different etching methods recently developed for revealing dislocations in $\mathrm{GaN}$ [4,6-12]. As a rule orthodox etching in molten salts (KOH [9], eutectic alloy of $\mathrm{KOH}-\mathrm{NaOH}=\mathrm{E}$ etch [11] and $\mathrm{E}+\mathrm{MgO}=\mathrm{E}+\mathrm{M}$ etch [13]) and hot acids $[11,14]$ results in formation of pits of different sizes. The attempts to attribute the size of pits to the type of dislocations showed unambiguously that the largest pits are formed on nano-pipes, i.e. open core screw dislocations $[11,14,15]$. Different morphologies of pits formed on edge, mixed and screw dislocations were reported after etching of $\mathrm{GaN}$ in $\mathrm{HCl}$ at $600{ }^{\circ} \mathrm{C}$ [16], while after etching in molten $\mathrm{KOH}$ Shiojima [12] found larger pits on mixed and smaller ones on edge dislocations. Etching in modified $\mathrm{E}+\mathrm{M}$ etch of MOCVD-grown hetero-epitaxial $\mathrm{GaN}$ layers lead to the conclusion that the largest pits are formed on nano-pipes and the smallest on edge dislocations [13]. It was tentatively concluded that the size of pits from the largest to the smallest follows the size of Burgers vectors of dislocations in GaN (nano-pipes, screw, mixed, edge, with the exception for the screw and mixed defects) [17]. In HVPE-grown GaN density of dislocations is usually lower than in the MOCVD-grown layers and in addition two or three size grades of pits are formed in place of four. This material was therefore chosen for establishing unequivocally the correspondence of the size of pits with the type of dislocations. In addition, etching of the HVPEgrown samples from numerous and different sources (both commercial vendors and scientific laboratories) showed that markedly different etching conditions have to be employed for revealing all dislocations. Consequently, the arguments will be presented on the reasons which might be responsible for the large scatter of the etching parameters and the path for establishing optimal etching conditions will be indicated.

\section{Experimental}

Etching experiments were performed using HVPE-grown thick hetero- and homoepitaxial GaN layers obtained from different sources. Both homo-epitaxial layers grown on $\mathrm{GaN}$ single crystals and hetero-epitaxial layers grown on sapphire or sapphire-based templates were studied. The basic parameters of the samples are summarized in Table 1. Some MOCVD-grown $\mathrm{GaN}$ layers were also used as the reference samples. Two orthodox etching systems were used and optimized for revealing dislocations in the form of etch pits: (i) $\mathrm{KOH}-\mathrm{NaOH}$ eutectic alloy (E) [11] and mixture of $\mathrm{H}_{2} \mathrm{SO}_{4}$ and $\mathrm{H}_{3} \mathrm{PO}_{4}$ (HH etch) [11]. The details on the mechanism of etching of $\mathrm{GaN}$ in these systems and on etching parameters were discussed earlier $[18,19]$. In order to ensure the reproducibility of etching, molten E was always kept 10 minutes at the chosen temperature before introducing the sample into the bath. In this way the moisture coming from the air due strong hydrophilic property of $\mathrm{KOH}$ and $\mathrm{NaOH}$ was removed from the molten etch. The temperature was measured directly in the molten $\mathrm{E}$ by a thermocouple protected by a Ni tube. After etching the surfaces were examined using differential interference contrast (DIC) optical microscopy, scanning electron microscopy (SEM) and Atomic Force Microscopy (AFM). From some samples conventional cross-sectional specimens were prepared and examined in TEM for defining the density and type of dislocations. For direct calibration of etch pits-dislocation type Focus Ion Beam (FIB) technique was used in order to cut out the TEM specimens at chosen pits. Thin foils were examined in a Philips CM30T microscope operating at $300 \mathrm{kV}$. Diffraction contrast images were obtained in dark field using two-beam conditions, or with reflections limited to a systematic row. The analysis of the dislocation type was done with the invisibility criterion

$g * b=0$, where $g$ is the reflection used for imaging and the $b$ is the Burger vector of the dislocation). For a wurtzite structure two different reflections are enough to reveal and all possible types of threading dislocations ( $\mathrm{g}=0002$ for mixed and screw, $\mathrm{g}=11-20$ or $\mathrm{g}=1-100$ for edge and mixed). In order to have a good spatial resolution of the dislocations core the images were recorded under weak beam imaging conditions.

3. Results and discussion 
3.1. Revealing different types of dislocations: thermodynamic factor.

Etching of HVPE-grown GaN layers in molten $\mathrm{E}$ etchant results in the formation of well defined hexagonal etch pits of density ranging $10^{6}$ up to $10^{9} \mathrm{~cm}^{-2}$ depending on the layer thickness, doping level and the employed growth technology. Apart from the standard etch pit density (EPD) counting and evaluation of the distribution of dislocations across the etched sample more information can be gained from the morphology of the etch features. As a rule two or three size-grades of pits (named e, $\mathrm{m}$ and $\mathrm{s}$ ) are formed depending on the growth parameters of the $\mathrm{GaN}$ sample and on the etching conditions. Very large scatter of the size ratio between these three size-grades of pits was observed and is evident from comparison of Figs 1a and 1b (in Fig.1a the largest (s) pits are 2 times larger then the smallest (e) ones while in Fig. 1b the difference in equivalent pits size ratio riches one order of magnitude). In addition from the detailed AFM section analysis of numerous pits it follows that the inclination angle of the side wall of small pits is in the range $10-25^{\circ}$ while it is $30-60^{\circ}$ for intermediate and large pits, see Fig. 2 . The slope of the side walls of pits stems from the interplay of vertical and horizontal etch rates (Fig. 3), assuming that the etch rate of the perfect surface is 0. From Cabrera's theory on the thermodynamics of pit formation [20] it follows that the critical value of the potential difference $(\Delta \mu)$ of a stable nucleus of a pit at the outcrop of a dislocation depends inversely on the elastic energy $\left(\mathrm{E}_{\mathrm{el}}\right)$ of the dislocation:

$\Delta \mu=2 \pi^{2} \Omega \gamma^{2} / \mathrm{E}_{\mathrm{el}}$

where: $\mathrm{E}_{\mathrm{el}}$ - elastic energy of dislocation, $\gamma$ - edge free energy, $\Omega$ - molecular volume.

The elastic energy value differs for different types of dislocations and is:

$\mathrm{E}_{\mathrm{s}}=\mathrm{Gb}^{2} \alpha, \mathrm{E}_{\mathrm{e}}=\mathrm{Gb}^{2} \alpha(1 / 1-v)$ and $\mathrm{E}_{\mathrm{m}}=\mathrm{Gb}^{2} \alpha\left(1-v \cos ^{2} \theta / 1-v\right)$ for screw, edge and mixed type of dislocations, respectively, [21] (where: G - shear modulus, b - Burgers vector, $\alpha$ - geometrical factor, $v$ is Poisson's constant and $\theta$ is the angle between screw and edge components of the Burgers vector of mixed dislocations).

In $\mathrm{GaN}$ epitaxial layers with wurtzite lattice all three types of threading dislocations (as well as nano-pipes, which have screw-type distortion of lattice [15]) are usually observed by TEM $[22,23]$, with the corresponding Burgers vectors:

$b_{e}=1 / 3<11-20>, \quad\left(b_{e}=a, b_{e}{ }^{2}=a^{2}\right)$,

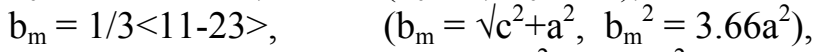

$b_{s}=[0001], \quad\left(b_{s}=c, b_{s}^{2}=2,66 a^{2}\right)$,

$\mathrm{b}_{\text {nano }}=\mathrm{n} \times \mathrm{b}_{\mathrm{s}}$ where $\mathrm{n}=1,2, \ldots$. , and $\mathrm{a}, \mathrm{c}$, are the lattice parameters.

Large differences in the magnitude of Burgers vectors, especially between edge type and screw/mixed type dislocations, imply that the shape and/or size of pits should be different depending on the type of dislocation. Assuming the presence of chemically pure lattice structure of etched GaN sample, the size of pits should depend on the magnitude of the Burgers vector of dislocations, i.e. the largest pits should be formed on mixed dislocations and the smallest on the edge ones. (The contribution of the lattice distortion around edge and mixed dislocations, represented by the Poisson constant, to the magnitude of the elastic energy is small, i.e. $7 \%$, taking $v=0,37$ after [24]. This is why the relationship: $\mathrm{E}_{\mathrm{el}}=\mathrm{Gb}^{2} \alpha$ is frequently used for all three types of dislocations [21]). Our previous etching and TEM study of MOCVD-grown GaN showed that the largest pits are formed on nano-pipes, smaller on mixed dislocations and the smallest on pure edge-type defects. Pure screw dislocations are seldom in this material (usually $2-4 \%$ of the whole population of dislocations) which made difficult establishing a one-to-one correlation between the pits and the screw dislocations. However, from the calculation of the different size pits density and quantification of different types of dislocations from TEM [25] it was concluded that the pits formed on the screw dislocations are larger than these formed on mixed-type dislocations [17].

The first attempt for unequivocal establishing this relationship was performed on HVPE-grown GaN using cross-sectional TEM approach, see Figs 4 and 5. This material has usually lower 
dislocation density as compared to the MOCVD-grown GaN. From the cross-section TEM images in Fig. 4 the density of dislocations was estimated to be $\sim 2 \times 10^{9} \mathrm{~cm}^{-2}$ and the relative density of different types of dislocations: $\mathrm{N}_{\text {screw }}: \mathrm{N}_{\text {mixed }}: \mathrm{N}_{\text {edge }}$ was found to be $\sim 20 \%: \sim 35 \%$ : $\sim 45 \%$. The same material was subsequently etched in molten $\mathrm{E}$ at low and high temperature, because such procedure allows revealing high and low energy dislocations separately [17]. The results of etching are set up in Fig. 5. The estimated density of large pits from three SEM images taken at different positions on the sample etched at $260^{\circ} \mathrm{C}$ is in the range $(1,5-2) \times 10^{8} \mathrm{~cm}^{-2}$, while the total EPD counted on the sample etched at $380^{\circ} \mathrm{C}$ is close to $1 \times 10^{9} \mathrm{~cm}^{-2}$. This means that the percentage of high energy dislocations responsible for the formation of large pits is in the range $15-20 \%$, which well fits to the percentage of screw dislocations obtained from the TEM image.

Since this semi-quantitative calibration might appear not convincing for concluding that the pits formed on screw dislocations are larger than the pits on mixed dislocations, we performed more detailed study using FIB preparation technique in order to establish the one-to-one association of different size-grade of pits with dislocations of different Burgers vector. Two HVPE-grown samples from different sources were etched in molten $E$ etchant under optimal conditions for revealing all dislocations. Cross-section thin foils were cut at the centers of pits of different size using FIB. Fig. 6a shows the etched surface of hetero-epitaxial GaN:Zn sample HVPE-4 with clearly distinguishable three size-grades of pits (s, m, e) and in Figs 6b-c there is a set of TEM images taken across two large pits, which confirms the association of s-pits with screw dislocations. Note also very high inclination angle of the side walls of the pits (close to $60^{\circ}$ ), which coincides well with the results of the AFM section analysis. Further confirmation for the formation of the largest pits on the screw-type dislocations was obtained from calibration etchingTEM on homo-epitaxial undoped GaN sample HVPE-1. Fig. 7a shows characteristic for this material pattern of etch pits, with numerous low angle dislocation boundaries (LAGB) represented by the rows of the smallest pits. The TEM specimens were cut from the large and intermediate size pits (which did not differ in size significantly) and separately along the LADB. TEM diffraction proved again that the largest pits are formed on screw dislocations while slightly smaller, but also deep pits, are formed on mixed-type dislocations, as demonstrated by the set of images in Fig. 7b-c. The edge-type dislocations were found in the specimen cut along the row of small pits (Fig. 7d), which, however, can not be recognized on the TEM image because these are shallow pits and they loose identity due to the small distance between dislocations and small angle of inclination of the side walls. Instead, shallow groove $(G)$ was formed and can be recognized on the surface of the TEM specimen in Fig. 7d.

The experimental evidence that the progression of pit sizes does not correlate well with the thermodynamic conditions of formation of pits derived from the magnitude of Burgers vector of screw and mixed dislocations implies that there must be another factor influencing the more efficient etching of screw as compared with mixed dislocations. Plausible arguments for explaining this seeming discrepancy can be derived from recent AFM studies of dislocations in different GaN layers. It has been shown using scanning Kelvin probe and conductive-AFM (CAFM) methods that edge and mixed dislocations are negatively charged (and not conductive) while pure screw dislocations are not charged [26]. From scanning surface potential microscopy (SSPM) study it was concluded that the charging effects on dislocations depend on the doping type and are the result of decoration [27]. Though the Coulomb forces were suggested to be responsible for the decoration of dislocations it is also reasonable to assume that the strain (deformation) field around the dislocations is the driving force for attracting foreign atoms such as dopant-atoms, impurities and non-stoichiometry related point defects. (In other III-V semiconductors, e.g. in melt-grown GaAs, the extent of impurity atmospheres around the grownin dislocations was of the order of tens of microns [28,29]. In the vapor-grown GaN this effect may be much smaller due to less favorable conditions for diffusion (lower relative growth temperature) as well as to a much higher density of dislocations to act as impurity sinks. Then the expected strain-field driven degree of decoration, which might be supported by the core charge 
(Coulomb) attraction forces should be more pronounced on edge and mixed dislocations due to the larger deformation of lattice around these type defects as compared to the screw dislocations (bond extension and compression around the mixed and edge dislocations are 6-7\% and 9-12\%, respectively, as was established from HR-TEM study [30]). Since the formation of the Cottrell atmosphere results in a release of strain around the linear defects, the $E_{\mathrm{el}}$ of edge and mixed dislocations would become smaller, which in turn would result in less favorable energetic condition for the formation of etch pits on these defects. Taking the effect of decoration into account it is possible to explain both the larger size of pits on screw then on mixed dislocations and a very small size of pits on edge dislocations in some samples (compare samples HVPE-1 and HVPE-2 in Fig. 1).

\subsection{Reliability of orthodox etching}

\subsubsection{Choosing etching conditions}

After etching of numerous HVPE-grown samples from several different laboratories and companies (see Table 1) the following conclusions can be drawn on the selection of "optimal" etching conditions:

- the conditions for revealing all dislocations varies in wide range of temperature $\left(360-480^{\circ} \mathrm{C}\right)$ and time (1-10 minutes) depending on the origin of the GaN sample. It was not possible to establish the exact reasons for such large scatter of the etching temperature because the growth parameters are usually not disclosed. It might be speculated, however, that apart from the type and level of intentional doping other technological data such as impurity level, ratio of the components in the gas phase (i.e. degree of non-stoichiometry), the growth temperature and cooling rate have influence on the energy of defects (i.g. via release of strain) and because of that on the appropriate etching parameters. Naturally the strongest influence of decoration can be expected on edge and mixed dislocations due to larger deformation of lattice around dislocation lines with the edge component as compared with pure screw defects. Indeed, the very small size of pits on the edge dislocations (see Figs $1 b, 5 b$ and $6 a$ ) seems to confirm this way of reasoning. Since the dislocations in HVPE-grown GaN are revealed in very broad range of temperature it can be anticipated that many erroneous estimations of the density of dislocations were performed due to the use of too low etching temperatures (see e.g. discrepancy reported in [9]). This refers not only to etching in molten salts $(\mathrm{KOH}, \mathrm{KOH}+\mathrm{NaOH}$ eutectic) but also more specifically to etching in hot acids $\left(\mathrm{H}_{2} \mathrm{SO}_{4}, \mathrm{H}_{3} \mathrm{PO}_{4}\right)$. In the latter etches, in addition to the use of the nonoptimized temperature [31], the kinetic factor may result under-estimation of EPD (see section 3.2.2);

- in order to find the optimal conditions of etching of a new HVPE-grown GaN sample it is recommended performing sequent etching starting at low temperature, e.g. $380^{\circ} \mathrm{C}$ and, depending on the result, gradually increase temperature and/or time of subsequent etching steps. Usually after the first etching step it is possible to choose the right parameters of the second etching run; - revealing of high energy defects (screw dislocations) can be performed in $\mathrm{E}$ etch at the temperature range $260-280^{\circ} \mathrm{C}$ using etching time $15-60$ minutes;

- it is worth mentioning that the MOCVD-grown GaN layers have much narrower range of optimal temperature $\left(400-420^{\circ} \mathrm{C}\right)$ for revealing all dislocations. This might be related to the narrower range of the optimal growth temperature and to different levels and species of contaminates in the MOCVD GaN layers.

\subsubsection{Kinetic factor}

In addition to the thermodynamics-related constraints for the formation of etch pits on dislocations there are also kinetics-related ones. The ideal orthodox defect-selective etch should not dissolve the perfect surface of a semiconductor $\left(\mathrm{V}_{\mathrm{P}}=0\right.$ in Fig. 3) and the rate of the horizontal movement of steps $\left(\mathrm{V}_{\mathrm{S}}\right)$ should not greatly exceed $\mathrm{V}_{\mathrm{N}}\left(\mathrm{V}_{\mathrm{S}} \leq 10 \mathrm{~V}_{\mathrm{N}}\right)$ [32]. Both $\mathrm{E}$ and $\mathrm{E}+\mathrm{M}$ etches fulfill this requirements while $\mathrm{HH}$ etch results in formation of very shallow pits (too 
large $\mathrm{V}_{\mathrm{S}}$ ). This may cause sweeping of small pits formed on edge dislocations and underestimation of the density of dislocations. Clear example of this phenomenon is shown in Fig. 8: etching in $\mathrm{HH}$ at $160^{\circ} \mathrm{C}$ (temperature recommended in [31]) did not reveal any dislocations while etching at higher temperature resulted in formation of shallow and therefore overlapping pits (Fig. $8 \mathrm{a}$ ), with inclination angles of the side walls well below $10^{\circ}$. The estimated density of defects was about $2.5 \times 10^{8} \mathrm{~cm}^{-2}$ while the real density of dislocations counted after E etching of the same material (Fig. 8b) is close to $2 \times 10^{9} \mathrm{~cm}^{-2}$. The same factor could have been responsible for the reported differences in EPD after $\mathrm{H}_{3} \mathrm{PO}_{4}$ etching and dislocation densities obtained from TEM [33]. It was shown that to avoid merging of pits and to obtain well defined deeper pits on GaN it is practical to add $\mathrm{Al} 3+$ or $\mathrm{Fe} 3+$ ions to $\mathrm{H}_{3} \mathrm{PO}_{4}$ etch [34]. The suggested role of foreign ions in the etching medium it to decrease the rate of horizontal step movement (Vs in Fig. 3), the method frequently used during etching of different single crystals [20].

Thick and quickly grown HVPE GaN layers are sometimes characterized by non-planar surface with numerous hillocks [35]. At the top of these hillocks AFM reveals the presence of either single screw or clustered screw and mixed-type dislocations, as shown in Fig. 9a. The presence of clustered defects with the screw component of the Burgers vector is a reason of formation of the growth hillocks, however during etching may contribute to the quick horizontal dissolution of $\mathrm{GaN}$ via formation of macro-steps. These etch features tend to form in the vicinity of closely situated large pits formed on screw or mixed dislocations in undoped GaN (steps marked by the arrows in Figs $1 \mathrm{~b}$ and 5a) and are frequently observed in $\mathrm{Zn}$ - and Fe-doped material, as shown in Fig. 9b. The areas between the large pits and macro-steps are usually free from small pits on edge dislocations because they can not develop due to the movement of macro-steps. A convincing argument of the role of macro-steps for "sweeping" small etch pits was obtained using two-steps E etching and AFM mapping at the same place of a GaN sample. The results are set up in Fig. 10. The small pits formed during the first etching and indicated by the arrows disappeared after second etching run due to the movement of the deep step marked $m$ in Fig. 10c.

\section{Concluding remarks}

1. Orthodox etching in E etchant of HVPE-grown GaN layers results in formation of etch pits usually in three distinct size grades. Using TEM on specimens prepared by conventional cross-section and cut by FIB methods, it was unequivocally established that the largest pits are formed on screw-, intermediate size pits on mixed- and the smallest ones on edge-type dislocations. This seemingly controversial result (the Burgers vectors and thus elastic energy of mixed dislocations is larger than the corresponding parameter of screw dislocations in wurtzite $\mathrm{GaN}$ ) can be potentially explained taking into account the possible release of strain followed by a decrease of elastic energy of dislocations with edge components, due to decoration by impurities, doping atoms and/or native point-like defects. The very large scatter of etching temperature required for revealing all dislocations on samples grown in different laboratories can be also attributed to variable impurity concentrations/distributions.

2. It is demonstrated that the screw-type dislocations can be revealed at much lower temperature than the other dislocations, especially the pure edge ones. The two-steps procedure of etching which ensures revealing all types of dislocations is suggested.

3. Both non-optimized etching temperature as well as kinetics-related factors for pit formation could be reasons for the incomplete etching of all dislocations and, hence, an undercounting of their density. This is especially in the etching of GaN in hot acids but might be also important for etching in molten salts of morphologically non-homogeneous thick HVPEgrown GaN layers and doped samples.

Acknowledgments

This work was financially supported by the Netherlands Foundation for Technical Research (STW). TEM work in LBNL was supported by the Air Force Office of Scientific Research under 
the order No. OGMORD 52K44134. The Lincoln Laboratory portion of this work was sponsored by The Office of Naval Research (ONR) under Air Force contract number FA8721-05-C0002. The opinions, interpretations, conclusions and recommendations are those of the authors and are not necessarily endorsed by the United States Government.

\section{References}

[1] F. Secco d'Aragona, J. Electrochem. Soc. 119 (1972) 948.

[2] K. Motoki, T. Okahisa, S. Nakahata, N. Matsumoto, H. Kimura, H. Kasai, K. Takemoto, K. Uematsu, M. Ueno, Y. Kumagai, A. Koukitu, H. Seki, J. Crystal Growth 237-239 (2002) 912.

[3] K. Yamamoto, H. Ishikawa, T. Egawa, T. Jimbo, M. Umeno, J. Crystal Growth 189/19 (1998) 575.

[4] P. Visconti, D. Huang, F. Yun, M.A. Reshchikov, T. King, R. Cingolani, J. Jasinski, Z. Liliental-Weber and H. Markoc, phys. stat. sol. (a) 190 (2002) 5.

[5] J.L. Weyher, Inst. Phys. Conf. Ser. No 146, IOP, Bristol, 1995, p. 399.

[6] J.L. Weyher, F. D. Tichelaar, H. W. Zandbergen, L. Macht and P. R. Hageman, J. Appl. Phys., 90 (2001) 6105.

[7] M. Albrecht, H.P. Strunk, J.L. Weyher, I. Grzegory, S. Porowski and T. Wosinski, J. Appl. Phys., 92 (2002) 2000.

[8] S. Lazar, J.L. Weyher, L. Macht, F.D. Tichelaar and H.W. Zandbergen, Eur. Phys. J. Appl. Phys., 27 (2004) 275.

[9] T. Kozawa, T. Kachi, T. Ohwaki, Y. Taga, N. Koide and M. Koike, J. Electrochem. Soc., 143 (1996) L17.

[10] C. Youtsey, L.T. Romano and I. Adesida, Appl. Phys. Lett., 73 (1998) 797.

[11] J. L. Weyher, P. D. Brown, J. L. Rouviere, T. Wosinski, A. R. A. Zauner and I. Grzegory, J. Cryst. Growth, 210 (2000) 151.

[12] K. Shiojima, J. Vac. Sci. Technol. B, 18 (2000) 37.

[13] G. Kamler, J. L. Weyher, I. Grzegory, E. Jezierska and T. Wosinski, J. Cryst. Growth, 246, (2002) 21.

[14] S.K. Hong, B.J. Kim, H.S. Park, Y. Park, S.Y. Yoon, T.I. Kim, J. Cryst. Growth 191 (1998) 275.

[15] S.K. Hong, T. Yao, B.J. Kim, S.Y. Yoon, T.I. Kim, Appl. Phys. Lett. 77 (2000) 82.

[16] T. Hino, S. Tomiya, T. Miyajima, K. Yanashima, S. Hashimoto and M. Ikeda, Appl. Phys. Lett., 76 (2000) 3421.

[17] J.L. Weyher, Superlattices and Microstructures, in press

[18] J.L. Weyher, L. Macht, G. Kamler, J. Borysiuk, I. Grzegory, phys. stat. sol. (c), No.3 (2003) 21.

[19] J.L. Weyher and L. Macht, Eur. Phys. J. Appl. Phys. 27 (2004) 37.

[20] K. Sangwal, Etching of Crystals, North-Holland, Amsterdam, 1987, pp. 87-160.

[21] D. Hull and D.J. Bacon, Introduction to dislocations Pergamon Press, Oxford, 1984, pp 71-90.

[22] D.M. Follstaedt, N.A. Missert, D.D. Koleske, C.C. Mitchell, K.C. Cross, Appl. Phys. Lett. 83 (2003) 4797.

[23] R. Datta, M.J. Kappers, J.S. Barnard, C.J. Humphreys, Appl. Phys. Lett. 85 (2004) 3411.

[24] J. Elsner, R. Jones, P.K. Sitch, V.D. Porezag, M. Elsner, Th. Frauenheim, M.I. Heggie, S. Öberg, P.R. Briddon, Phys. Rev. Lett., 79 (1997) 3672.

[25] F.D. Tichelaar, H.W. Zandbergen, Internal report 1000905a, Delft, National Center HREM, 12 February 2001.

[26] B.S. Simpkins, E.T. Yu, P. Waltereit, J.S. Speck, J. Appl. Phys. 94 (2003) 1448.

[27] A. Krtschil, A. Dadgar, A. Krost, J. Crystal Growth, 248 (2003) 542.

[28] C. Frigeri, J.L. Weyher, J. Appl. Phys. 65 (1989) 4646.

[29] J.L. Weyher, P.J. van der Wel, C. Frigeri, Semicond. Sci. Technol. 7 (1992) A249.

[30] D. Wang, M. Ichikawa, S. Yosida, Phil. Mag. Lett. 82 (2002) 119.

[31] P. Visconti, D. Huang, M.A. Reshchikov, F. Yun, R. Cingolani, D.J. Smith, J. Jasinski. W. Swider, Z. Liliental-Weber, H. Markoç, Mat. Sci. Eng. B93 (2002) 229.

[32] R.B. Heimann, Principles of Chemical Etching-The Art and Science of Etching Crystals in: Crystals: Growth, Properties and Applications 8, ed. J. Grabmaier, Springer-Verlag, Berlin, 1982, pp. 173-224.

[33] J. Jasinski, W. Swider, Z. Liliental-Weber, P. Visconti, K.M. Jones, M.A. Reshchikov, F. Yun, H. Markoç, S.S. Park, K.Y. Lee, Appl. Phys. Lett. 78 (2001) 2297.

[34] M.G. Mynbaeva, Yu.V. Melnik, A.K. Kryganovskii and K.D. Mynbaev, Electrochem Sol.-State Lett., 2 (1999) 404. 
[35] B. Łucznik. B. Pastuszka, I. Grzegory. M. Bockowski. G. Kamler. E. Litwin-Staszewska, S. Porowski, J. Crystal Growth 281 (2005) 38.

Table 1.

Characteristics of GaN samples used in this study.

\begin{tabular}{|l||c|c|c||}
\hline $\begin{array}{l}\text { Growth method } \\
\text { Symbol of samples }\end{array}$ & Number of samples & $\begin{array}{c}\text { Doping element } \\
\text { (intentional) }\end{array}$ & $\begin{array}{c}\text { Electrical } \\
\text { characteristic }\end{array}$ \\
\hline \hline HVPE-1 & 6 & Non-doped & Conductive \\
\hline HVPE-2 & 1 & Non-doped & Conductive \\
\hline HVPE-3 & 2 & $\mathrm{Zn}$ & $\mathrm{SI}$ \\
\hline HVPE-4 & 3 & $\mathrm{Zn}$ & SI \\
\hline HVPE-5 & 1 & $\mathrm{Fe}$ & SI \\
\hline HVPE-6 & 1 & Non-doped & Conductive \\
\hline HVPE-7 & 5 & Non-doped & Conductive \\
\hline MOCVD-1 & 1 & $\mathrm{Si}$ & n-type \\
\hline
\end{tabular}

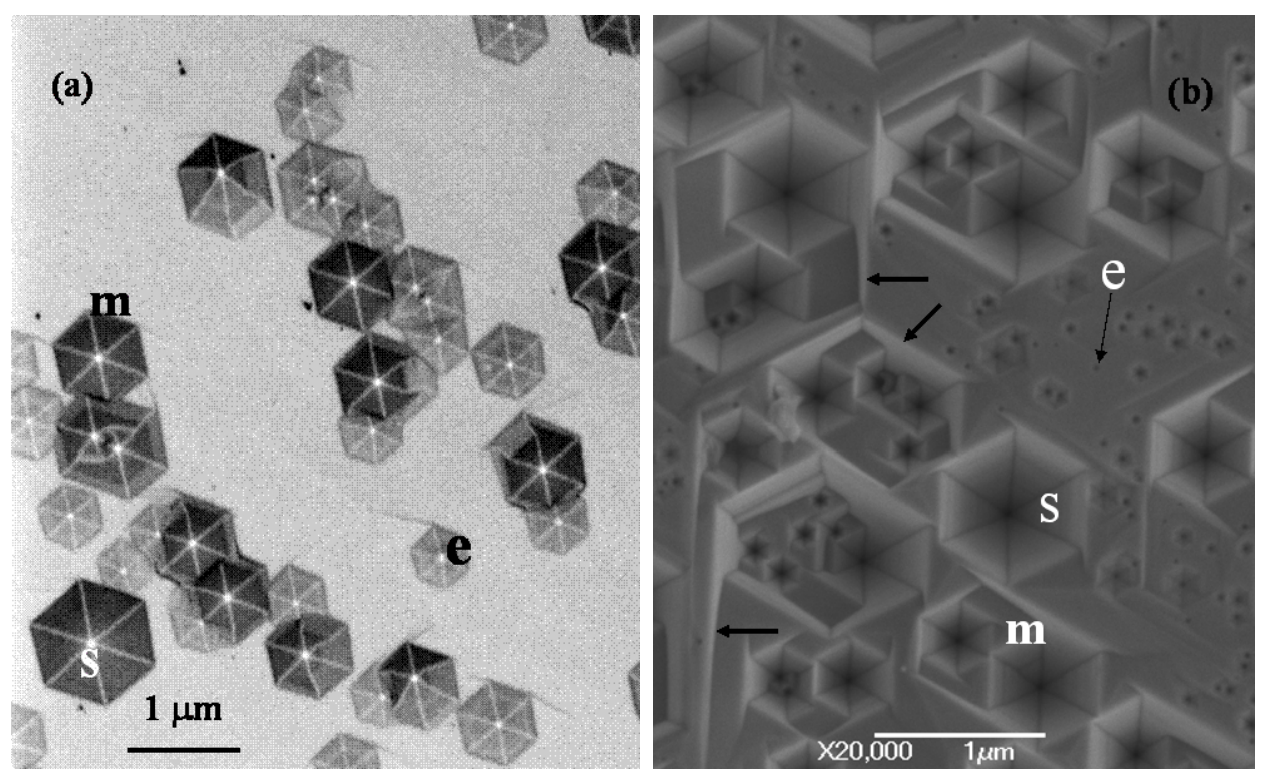

Fig. 1. SEM images of GaN samples HVPE-1 (a) and HVPE-2 (b) after E etching at $460^{\circ} \mathrm{C}$ and $400^{\circ} \mathrm{C}$, respectively.
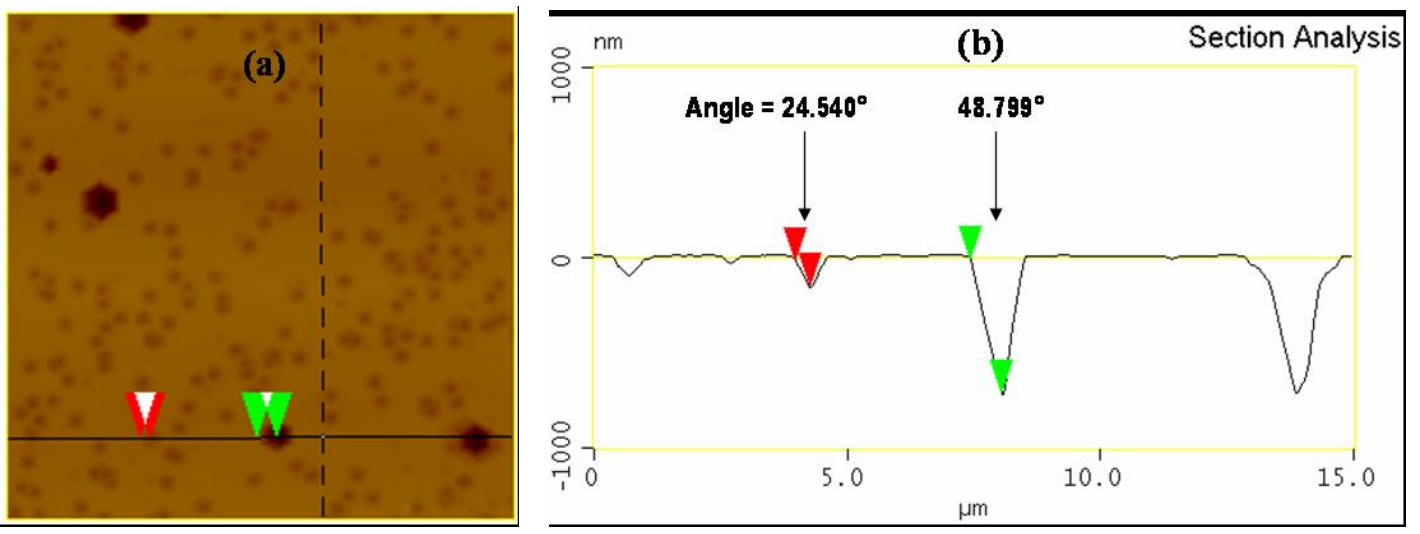

Fig. 2. AFM image (a) and section analysis (b) of large and small size pits formed on different type dislocations in GaN sample HVPE-3 after etching in molten $\mathrm{E}$ at $380^{\circ} \mathrm{C}$. 


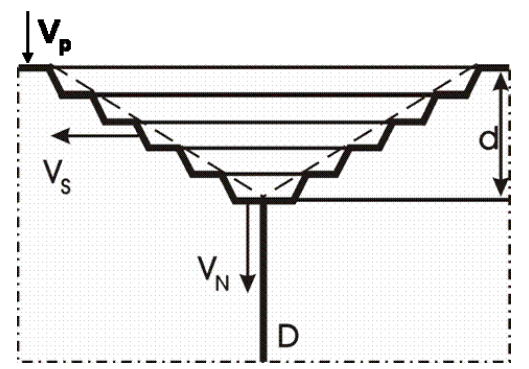

Fig. 3. Schematic drawing of an etch pit originating on a dislocations (D). It can be characterized by the inclination angle of the side walls which is the result of the ratio of nucleation rate $\left(\mathrm{V}_{\mathrm{N}}\right)$ and step propagation velocity $\left(\mathrm{V}_{\mathrm{S}}\right)$. The vertical etch rate at the outcrop of dislocation $\mathrm{V}_{\mathrm{N}}$ is the rate of nucleation of the pit.
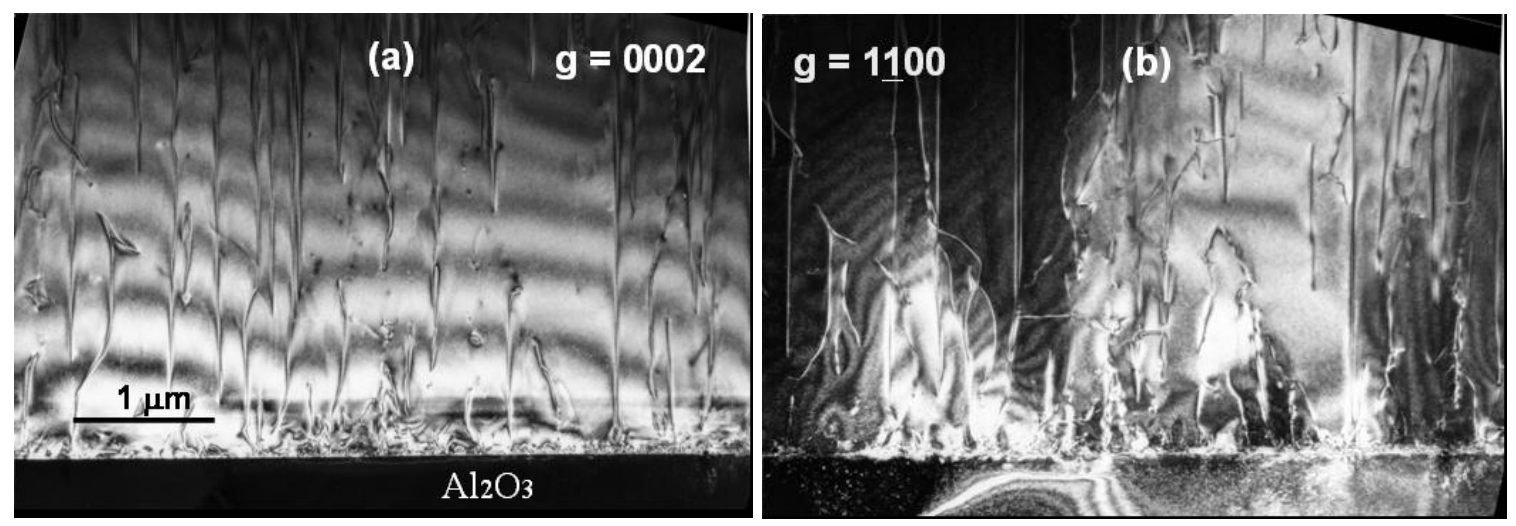

Fig. 4. Cross-section TEM images showing different types of dislocations in GaN sample HVPE2: (a) mixed and screw and (b) mixed and edge type dislocations are visible.
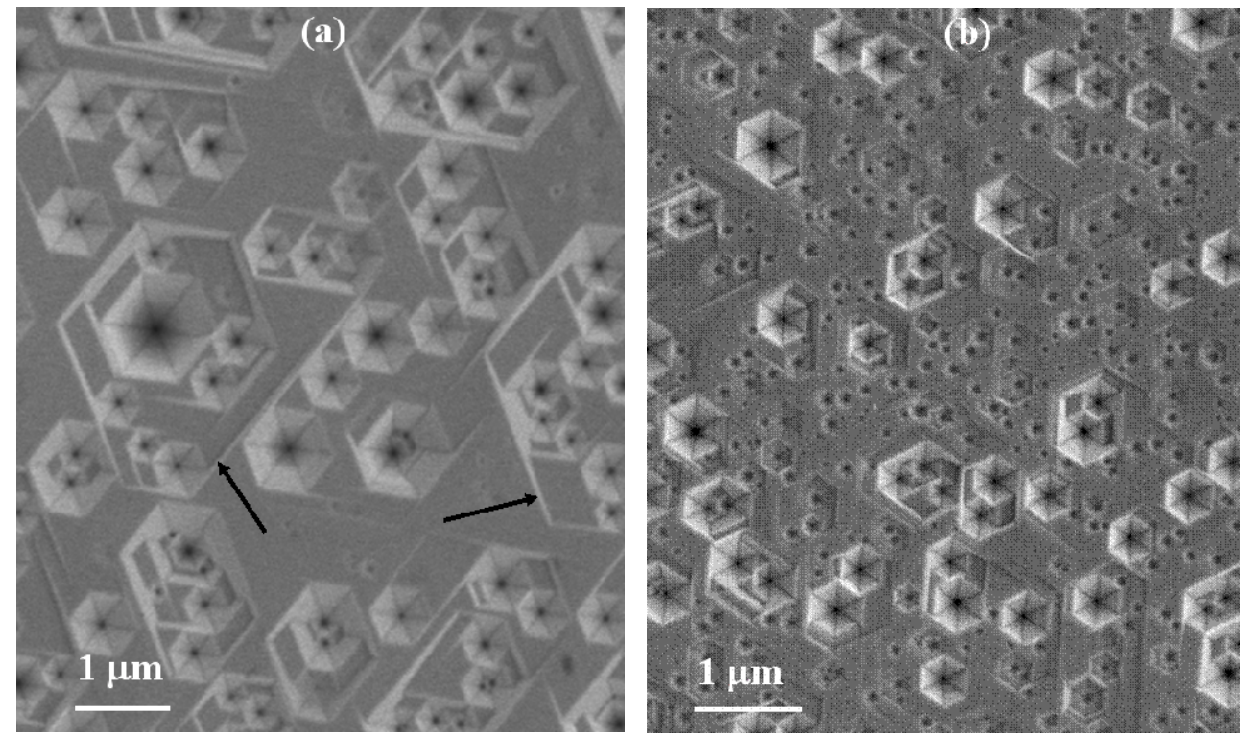

Fig.5. SEM images of the same GaN sample HVPE-2 as in Figs $1 \mathrm{~b}$ and 4, etched in molten $\mathrm{E}$ at (a) $260 / 15\left(\mathrm{EPD} \sim 1,5 \times 10^{8} \mathrm{~cm}^{-2}\right)$ and (b) $380 / 1,5\left(\mathrm{EPD} \sim 1 \times 10^{9} \mathrm{~cm}^{-2}\right)$. 

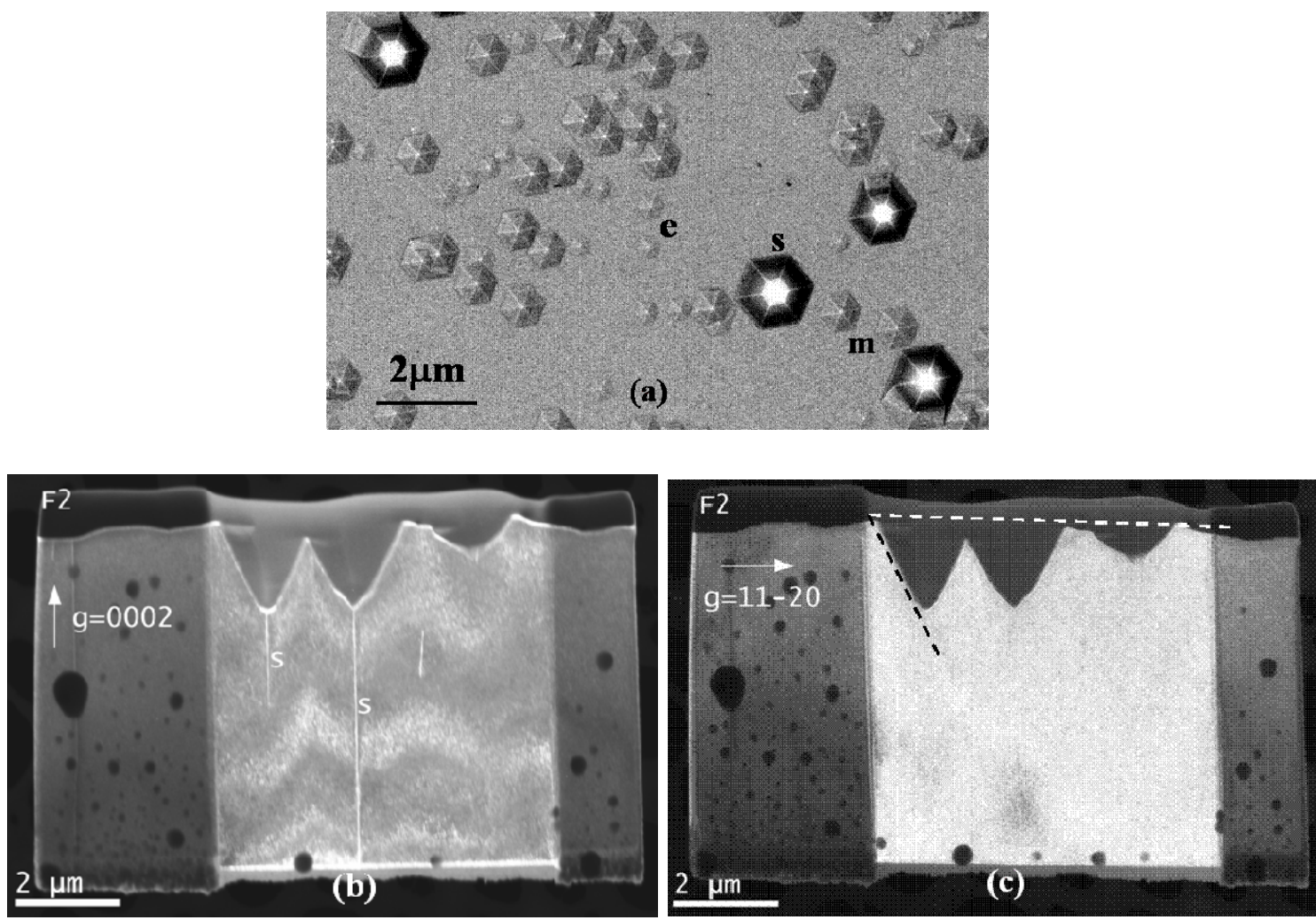

Fig. 6. (a) SEM image of the E-etched sample HVPE-4 and (b,c) BF TEM images taken with different diffraction conditions on the specimen cut at the centre of two s-type pits. The dashed lines form an angle of $\sim 60^{\circ}$ which defines the inclination of the side walls of pits.

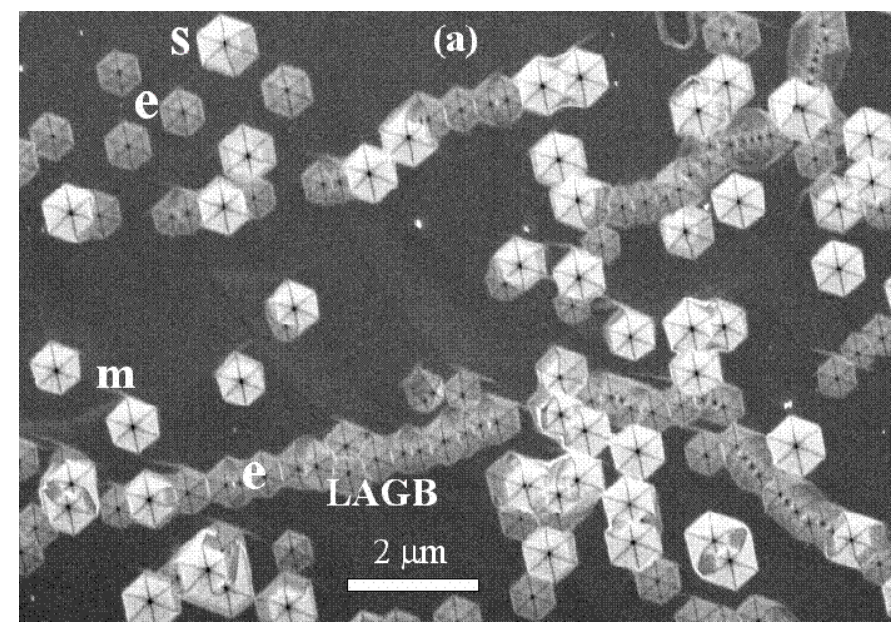



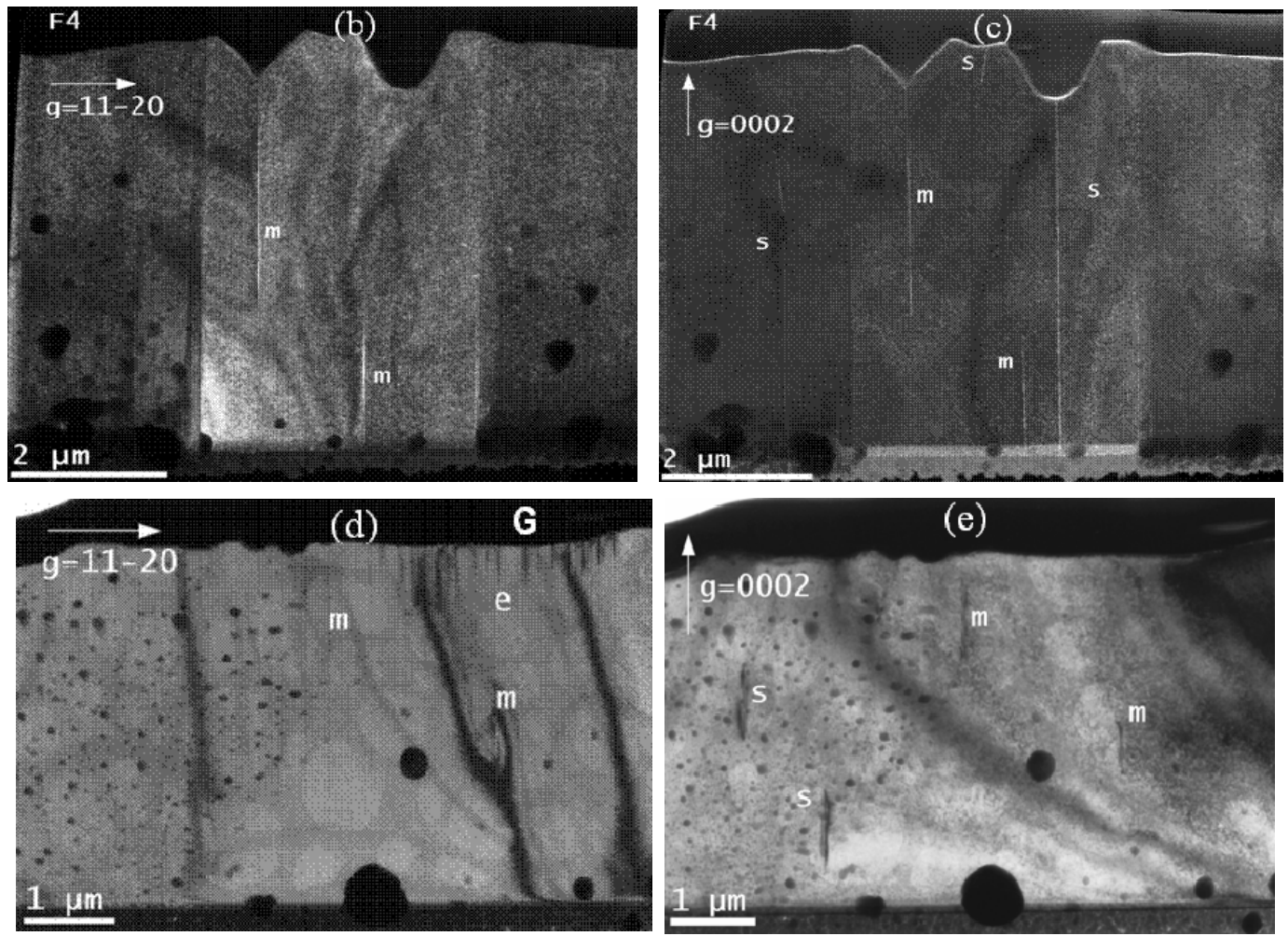

Fig. 7. (a) SEM image of sample HVPE-1 after E-etching. (b-e) TEM images taken with different diffraction conditions on the specimens cut across the $s$ and $m$ pits $(b, c)$ and across e-pits forming $\operatorname{LAGB}(\mathrm{d}, \mathrm{e})$.
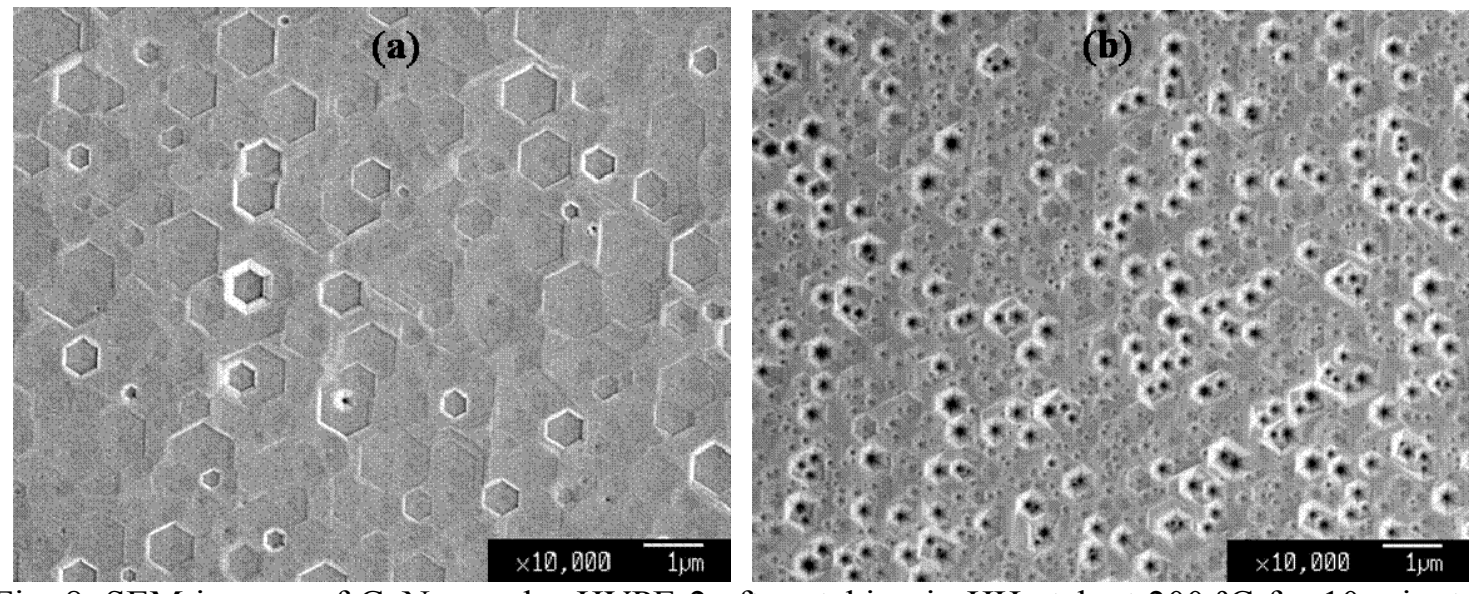

Fig. 8. SEM images of GaN samples HVPE-2 after etching in $\mathrm{HH}$ etch at $200{ }^{\circ} \mathrm{C}$ for 10 minutes (a) and after E etching at $420^{\circ} \mathrm{C}$ for 12 minutes (b). 

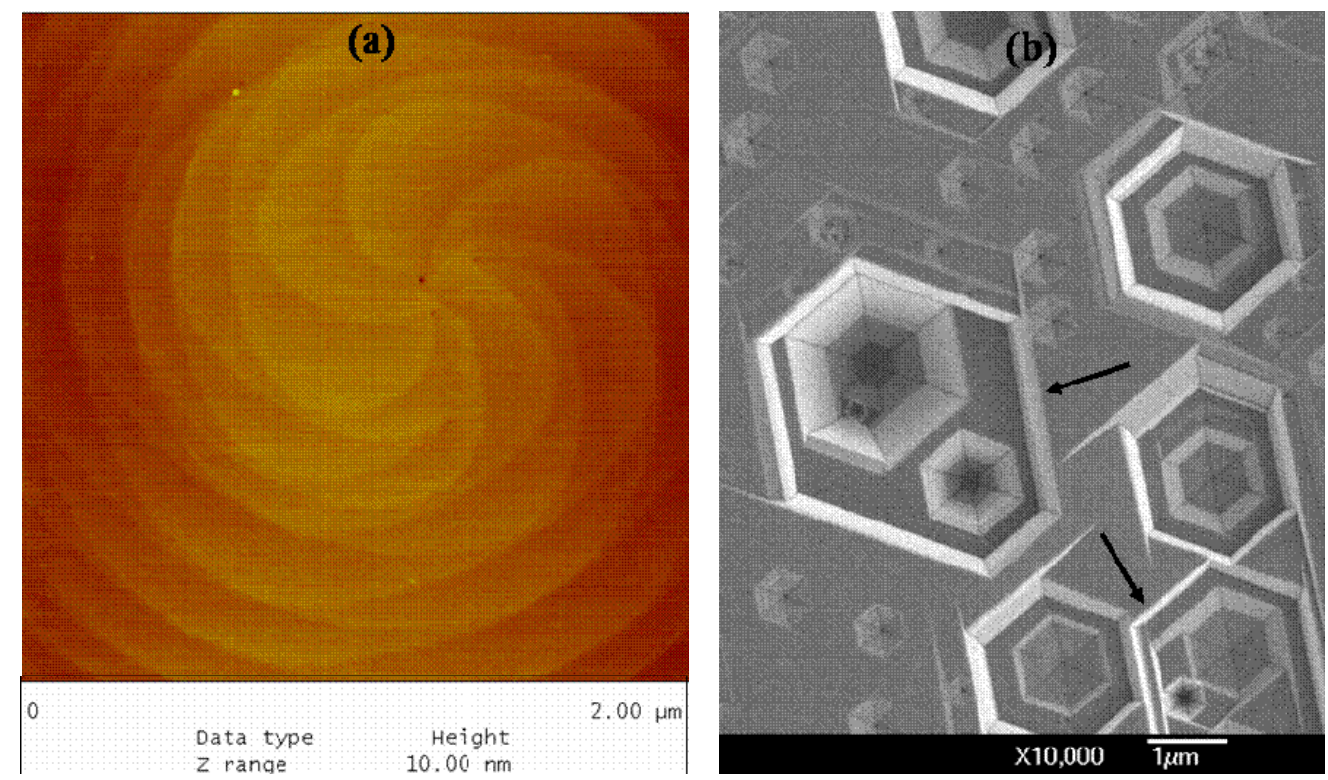

Fig. 9. (a) AFM image taken at the top of a growth hillock on the as-grown HVPE-4 sample. (b) SEM image of pits and macro-steps formed during E-etching of Zn-doped GaN sample HVPE-3.

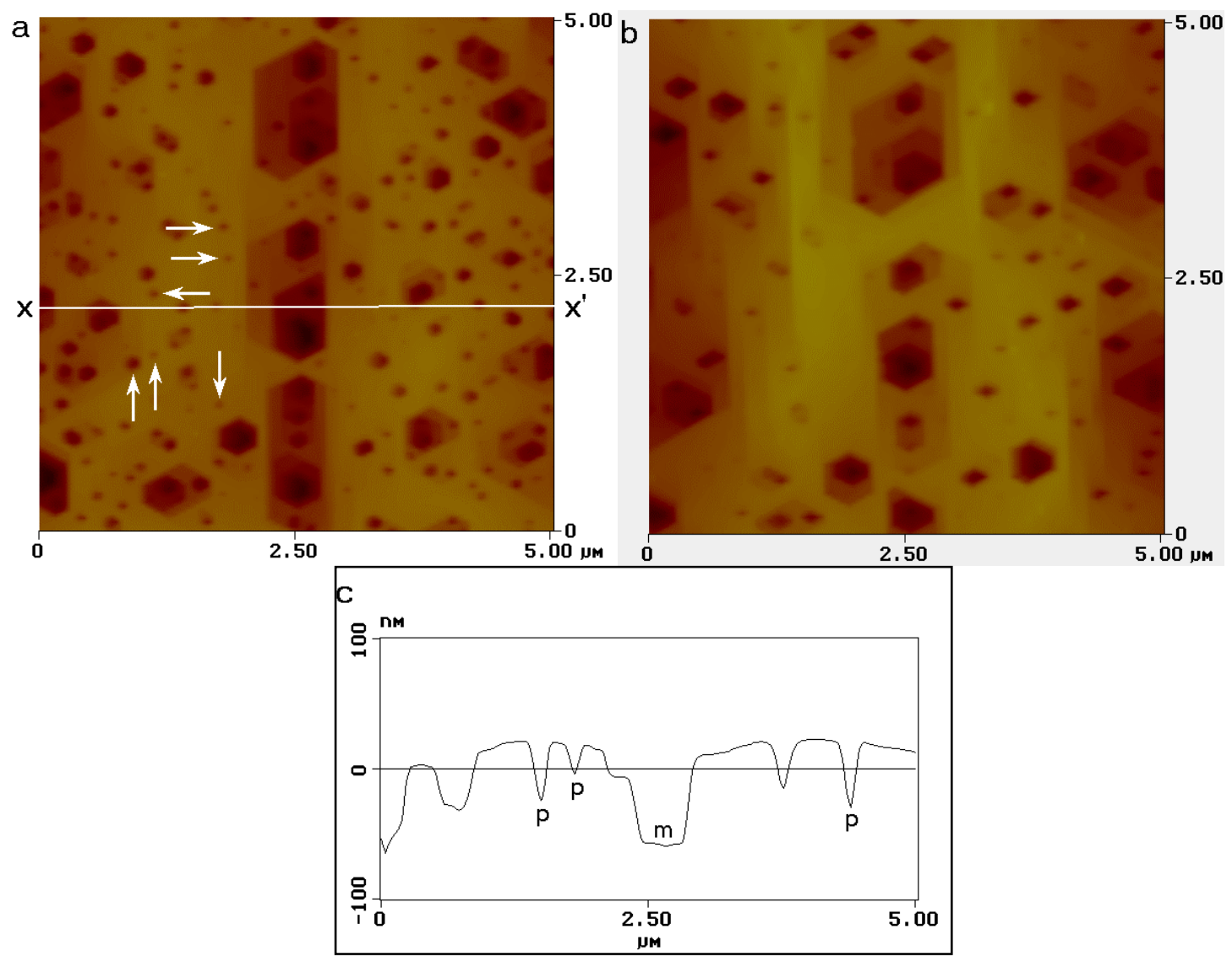

Fig. 10. AFM mapping (a, b) and section along the $\mathrm{x}-\mathrm{x}$ ' line (c) after first $\mathrm{E}$ etching at $400^{\circ} \mathrm{C}$ for 2 minutes (a) and subsequent the same etching procedure (b) on GaN sample MOCVD-1. p small pits, m - deep macro-step. 